\title{
DEVELOPMENT OF HIGH-TECH INDUSTRIES: FOREIGN EXPERIENCE
}

\author{
Vitaly Makoveev ${ }^{1}$, Liliya Mukhametova ${ }^{2}$ \\ ${ }^{1}$ Vologda state University \\ ${ }^{2}$ Kazan State Power Engineering University, str. Krasnoselskaya, 51, 420066, Kazan, Russia
}

\begin{abstract}
Sustainable long-term development of the energy sector is impossible without a developed manufacturing industry and especially machine-building enterprises. The article considers the experience of developed and developing countries in the field of support and stimulation of innovative processes in industrial enterprises. It is concluded that one of the main roles in the activation of innovation processes in industry is played by state authorities and management.
\end{abstract}

\section{Introduction}

The transition of the Russian economy to the path of innovative development is one of the national priorities for its further socio-economic development. It contributes to high-quality and sustainable economic growth and makes the country less dependent on foreign markets. In this regard, of particular interest is the experience of countries that are world leaders in innovative development and major manufacturers of high-tech products, such as the United States, Germany, Japan, as well as countries that have recently shown high growth rates (China, India, etc.).

Analyzing the world experience of the formation of high-tech industries, we can conclude that it was mainly based on comprehensive targeted scientific and technical programs initiated by the governments of countries and financed from the state budget.

For example, targeted government support for hightech and technically advanced industries has provided the United States with a leading position in global scientific and technological development. In the United States, industrial policy is based on a reasonable choice of priorities for state support and adequate forms of financial incentives for certain industries and industries that are of national importance and are necessary to maintain priority in specific areas of world production, where the country may have significant advantages over other participants in the international division of labor. The goal of industrial policy in the United States is to make it a kind of research and development ground and ensure the country's superiority in the world in terms of scientific and technological progress [9].

The main principle of the development of the industrial sector in the United States is recognized as the ability to quickly change the structure of production in connection with scientific and technical evolution and shifting priorities in market demand [9]. To achieve this goal, the state exercises control over industries and sectors of national importance and influences the situation in them, using mainly indirect methods of stimulation.

An example of such methods is tax incentives for $\mathrm{R}$ $\& d$. In the United States, it is implemented not only at the Federal level, but also at the state level, as many of them provide additional benefits to enterprises engaged in R \& d. A Prime example of tax benefits for R \& d companies is the investment tax credit. In the United States, this benefit has been introduced since 1981, and calculations show that every dollar spent as an investment tax credit increases economic activity in the United States by two dollars [3].

Also, the characteristic features of the development of the American innovation system include the emergence of the main innovation institutions (technoparks and venture funds) that are virtually independent of state authorities, and the high activity of small innovative companies, which is primarily due to the existence of special state programs to support them, as well as the development and availability of venture capital - the main source of funds [8].

In Germany, the main priorities for the development of high-tech industries are determined by various state strategies and programs. Since the beginning of the 80ies of the twentieth century, Germany has made efforts to create a strategy for industrial development and innovation.

In 2002, the German innovation policy concept was developed. Its main priorities were: the formation of an innovative culture, the creation of a framework environment that promotes innovation, and the implementation of research results in innovation. In 2006, the strategy of innovation and technological development was approved, which defined the main directions of actions in the national innovation sphere and tools for their implementation. This document sets 
new priorities for Germany in the technological sphere, taking into account global trends in the development of science, technology and technology [10].

To implement the priorities, the Federal government has initiated a number of projects aimed at creating effective interaction between science and business, and developing clusters that develop new technologies. They combine industry and academic institutions in research activities and are stimulated by the state through special programs, such as the initiative to create professional connections in specific areas of competence, a competition for the title of a leading cluster, and innovative alliances [11].

Innovation alliances are a new tool in conducting research and innovation policy. Firms with the same technology platform are United in innovation alliances. They may include state research organizations. Currently, nine innovative alliances have been formed in the field of energy, electronics, optics, and Biomedicine.

The decision to create an innovation Alliance is made taking into account the following criteria: private business must provide funding for a significant share of $\mathrm{R} \& \mathrm{~d}$, the final results of activities must be of great public importance, and the members of the Alliance must have adequate research potential and industrial base [1].

All these three programs represent another step towards effective interaction between science and industry in the German innovation process.

Among the instruments of financial support in Germany may be noted the provision of state subsidies, preferential tax terms, help with the formation of equity capital, loans and loans and state guarantees, preferential terms of land use. Venture capital financing is not as widespread in Germany as it is in the United States.it is mainly used in the final stages of the innovation process.

The German experience discussed above clearly demonstrates that the main success factors in the longterm development of innovative processes in industrial enterprises are the active role of the state, which consists in formulating the main development priorities in this area, developing strategies and programs for further development, and ensuring close interaction between science and business.

In Japan, the main role in coordinating innovation processes, as well as in Germany, is played by public authorities, developing various strategies and programs for innovative development. However, most of the scientific and technical developments of an applied nature are carried out in the research laboratories of large industrial corporations and remain within the same corporations without widespread transfer to potential users across the relevant industry. State scientific research is mainly of a fundamental nature, and the degree of its implementation in practice remains low [8].

To stimulate the intensive penetration of innovations into the market, the Japanese government helps businesses develop new technologies through a system of investments, loans, and guarantees. This system allows the state to concentrate small financial investments on priority sectors and simultaneously attract a large number of industrial enterprises to innovative projects [2].

One of the main directions of development of innovation processes in Japan is the creation and development of technopolises. Back in the 1980s, the country's highest authorities began implementing a largescale program to create them. In accordance with the developed program "Technopolis", it was planned to create about 20 scientific and technical zones, called technopolises, in certain prefectures of Japan that were lagging behind in economic development. Residents of technopolises are provided with various types of tax benefits and assistance in lending. For example, enterprises operating in the new technology industries were given the opportunity to write off $30 \%$ of the cost of equipment and $15 \%$ of the cost of buildings and structures in the first year, the state paid a third of the cost of joint research by laboratories and small firms [6]. Technopolises promote the integration of University science and industrial production.

Thus, the leading position in the markets of high-tech products in Japan was ensured by the active role of the state in regulating innovation processes, through largescale financing through state banks and the diversity and flexibility of the policy of benefits for participants in industrial entities (such as technopolises, production clusters, etc.).

Now let's look at the experience of China, since its economy is one of the most dynamically developing economies in the world. In $2000-2011$, the average annual growth rate of the country's GDP was about $10 \%$ [6]. In terms of the development of science and technology, as well as in the export of machine-building products, the country takes a leading position in the world, second only to the United States today [4].

The outstanding growth in innovation achievements observed during the "eleventh five-year plan" was achieved through active state support.

In China, the state is the main initiator of economic modernization with a focus on its own development and the main source of $\mathrm{R} \& \mathrm{~d}$ financing, and the role of the private sector is to develop technologies based on its own research and market development of innovations [4].

In the 1980s, China's innovation policy aimed at modernizing the industrial sector was implemented through the implementation of targeted programs aimed primarily at the development of foreign technologies. The formation of innovative business was carried out through the creation of preferential administrativeterritorial formations, such as special economic zones (SEZs), zones of trade and economic development, industrial parks, etc. [8]. Adopted in 1988. the Torch program, aimed at the development of science and technology, has chosen the construction of technology parks as a key factor in the development of modern technologies. Currently, China has created 57 such zones for the development of new and high technologies at the state level. Such rapid growth of technoparks in China, as well as significant investments from foreign investors in their development, is explained by the specific 
conditions provided by the Chinese Government to residents of technoparks.

Such conditions include: a reduced income tax rate, recognition of even $100 \%$ of foreign capital, complete freedom to transfer funds abroad by foreign individuals and legal entities, exemption from income tax in case of reinvestment of income in the economy of free economic zones, and a long term of cooperation agreements [4].

In addition to preferential conditions for innovation, the Chinese Government pays special attention to the human resources potential of science.

Professional development is mainly carried out by attracting foreign specialists and sending national scientific personnel to study abroad. Thus, in 2009, 51 thousand Chinese citizens received education abroad, and 14 new foreign channels for higher education were opened. In addition, in 2009, a total of 480 thousand foreign scientific and technical specialists were attracted to work in China [8].

The Chinese government not only promotes the regular sending of scientists and engineers for retraining abroad at the expense of the state, but also pursues an active policy aimed at the return of Chinese scientists to the country. In 2007, the Chinese authorities adopted a decree that obliges students who studied abroad at the expense of the state to work at least two years after graduation in their home country before continuing their postgraduate studies, otherwise they will have to pay a large fine. For scientists and engineers who have returned from abroad, the state provides four-year research grants of up to 1 million yuan. This money is used to create business incubators and technology parks at universities. This state policy has led to the fact that about $60 \%$ of academics in China are repatriates [4].

A striking example of rapid and successful development and implementation of our own innovations is the situation with power equipment in China.

Due to the fact that China's rapid economic growth is accompanied by a large-scale increase in energy consumption (primarily hydrocarbon fuel and coal), greenhouse gas emissions are significantly increasing.

The key factor in reducing harmful emissions into the atmosphere is considered to be the modernization of energy by updating equipment, the development of renewable energy sources, and the introduction of innovative technologies. China imported such technologies and equipment from the United States and Switzerland. But in 2004. China has started to develop its own production of such equipment and carry out mass installation of new power units at the country's thermal power plants.

Significant progress has been made in solar energy. China has become the largest factory for the production of solar panels, $95 \%$ of which is exported. Such a rapid growth of innovative technologies in China's energy sector is provided by strong state support, the main measures of which are state subsidies and soft loans. For example, at most enterprises, the state sponsors the production of the first 50 samples of a new type of product [5].
Another similar example is Norway's experience in developing and implementing innovations in the field of heavy engineering.

The discovery of the first oil field in Norway in 1969 created a demand for drilling and field equipment. Further discovery of new oil and gas fields contributed to an increase in production and, consequently, the demand for the necessary oil and gas equipment.

The Norwegian government was faced with a choice: either buy oil and gas equipment for import,or start its own production. The country's government has chosen to use oil rents to create a new industry that will generate added value even after the fields run out.

The main measures taken by the Norwegian authorities for the development of oil and gas engineering and services were [7]:

- the requirement for oil-producing companies to include Norwegian producers of oil and gas equipment in tenders for its supply, but only if their products meet the customer's requirements (decree on offshore exploration of 1972);

- preference on the part of the state for producing companies that use more domestic equipment;

- an active policy in the field of scientific research, which stipulated that from 1979 to 1994, oil and gas companies were forced to improve the skills of scientists and Finance development within the framework of technological agreements with Norwegian research institutes, which are obliged to conclude them;

- invitation of foreign professors at the expense of the state to train domestic specialists in leading universities in Norway.

As a result, the share of Norwegian participation in the development of oil and gas fields reached $90 \%$. This policy served as a powerful incentive to the development of the entire Norwegian engineering industry, as it created a demand for products from other sectors of the engineering industry and for new technologies [7].

The development of innovation processes in India is mainly carried out in the field of IT technologies through the creation of technology parks, the construction of which was started in 1984.

Since 1984, the government Agency for the creation of science and technology parks to support science and technology (STEP) has created about 30 such parks, primarily focused on exports. Residents of technology parks are provided with significant tax and customs benefits and are not subject to restrictions on foreign investment in Indian companies.

An important role in the development of technoparks is played by the state policy aimed at ensuring communication between enterprises and universities, including foreign ones, and the development of Internet infrastructure [4].

In India, technical education has reached a high level of development, which trains highly qualified personnel for the development of industry, and many students and postgraduates are sent for internships in the United States and great Britain. Unlike China, which has focused on low labor costs, India has focused on quality. About 3 million bachelors are graduated annually, most 
of them are fluent in English and are in high demand in large corporations in developed countries.

The main source of $\mathrm{R} \& \mathrm{~d}$ funding in India is venture capital. It is provided by the National venture Fund for software and information technology and the Fund for the development of small and medium-sized enterprises.

Thus, the steps taken by the Indian authorities to create high-tech industries through the organization of technology parks, active sending of students and postgraduates abroad, and state support for small and medium-sized enterprises engaged in $\mathrm{R} \& \mathrm{~d}$ have made this country one of the leaders in the development of it technologies and made it a global talent pool of young specialists in this field.

The experience of developed and developing countries shows that the high-tech industrial complex is the innovative core of industry and the point of growth of the entire economy. Therefore, it is important to create conditions for the development of high-tech industries, which include those industries in which the share of expenditures on industrial science is at least 4.5 $-5 \%$ in the shipped products, and high-tech industries are more than $10 \%$ [12].

Summarizing the considered foreign experience in the development and implementation of innovations, we can conclude that the main initiator and coordinator in the development of innovation processes in the industrial sector are state authorities and management.

First, the state plays a key role in financing R \& d, implementing it in various forms: direct financing, grants and other grants (China, Japan, Germany), or support in the form of government orders or purchases (USA, UK).

Second, companies that introduce new technologies and produce high-tech products were granted various benefits by the state, including tax benefits (India, the United States, and the United Kingdom). Such measures helped attract investment and new firms to the territory of the countries.

Third, the state coordinates and establishes relationships between research centers and industrial enterprises (Germany, USA, Japan). The interaction of business and science makes it possible to speed up the process of implementing existing innovations in industrial production and increase its efficiency and competitiveness.

Fourth, the development of innovation processes was achieved through the state's initiative to create and develop territorial production systems (production clusters, technoparks, technopolises, industrial parks). With their help, a high level of development of relations between all participants in production, science and education was ensured.

\section{References}

1. K. Andrianov, Germany and innovation, Modern Europe, 4, 103-116 (2012).

2. G. Bakosh, Technological policy in Japan: lessons for Eastern Europe, Questions of economy, 9,.100113 (1997).
3. O.I. Borisov, Favorable tax climate for innovative activity as anti-crisis measure in Russia and foreign countries, Taxes, 3, 37-45 (2011).

4. Yu. Emelyanov, National innovation system in China and India, Problems of management theory and practice, 12, 27-38 (2011).

5. V. Klavdienko, China's Economy: innovation and "greening", Problems of management theory and practice, 4, 16-24 (2012).

6. A.A. Lavrov, Features of functioning of high-tech clusters in China and Japan [Electronic resource], Mode of access: http://sun.tsu.ru/mminfo/000063105/329/image/329182.pdf

7. V. N. Borisov, I. A. Budanov, A. K. Moiseev, V. S. Panfilov, Necessary conditions for modernization of the Russian manufacturing industry on the example of heavy engineering, Problems of forecasting, 1, 20-37 (2012).

8. Review of international experience in innovative development [Electronic resource]. - Mode of access:

http://www.nanonewsnet.ru/articles/2011/obzormezhdunarodnogo-opyta-innovatsionnogo-razvitiya

9. E. Pilipenko, Yu. Batalov, Formation of high-tech industries: sources of financing, Problems of management theory and practice, 11-12, 176-181 (2012).

10. G. Rainer, Innovative policy assumes innovative entrepreneurship [Electronic resource], access Mode: http://elementmag.kz/?p=141

11. T.OSapozhenkova, T. O. FRG and the innovation process [Text] / T. O. Sapozhenkova // Modern Europe. - 2012. - no. 2. - Pp. 109-122.

12. scientific and technical indicators-2008. Washington: NSA, 2008 [Electronic resource]. Mode of access: http://www.nsf.gov/statistics/seind08/.

13. D. Mazhitov, M. Ermilova, E. Altukhova, T. Maksimova, and O. Zhdanova, Development of Technologies and Processes in Environmental Management, E3S Web of Conferences 135, 04045 (2019). doi:10.1051/e3sconf/201913504045. 